\title{
Crisis and Ecological Restoration
}

We have a crisis of crises. The media dwell on crises large and small, personal and global. Meanwhile, politicians seem to live for crises-including those politicians who constantly tell us that too much government is the problem, not the solution. Perceiving a demand, universities now offer courses in crisis communication ("spin doctoring") and crisis management. And lest we forget, people concerned about the environment continue to use the term "crisis" to support and promote their causes.

Sociologists and psychologists typically describe crises as community or personal turning points. Scientists and historians are more likely to characterize them as large-scale disturbance events or paradigm shifts. However we describe them, true crises are distinguished by periods of uncertainty and vulnerability, coupled with a desire for positive change. It is in these periods that people look for new answers-for creative ways to restore order.

Many people have described the condition of forested ecosystems in the western United States as critical. I agree with this assessment, not in the sense of an ecological emergency, but in the larger context of an ecological-political-social crisis. As a nation, we have not managed our forested ecosystems properly. We have logged and grazed forests without much thought for their future. Moreover, we have built economic and social structures that depend on such subsidized activities. We have also suppressed fires in fire-dependent forests to the point where they are overgrown and prone to large-scale conflagrations. In addition, we have done a poor job of zoning or placing other restrictions on building homes in fire-prone areas. Much of this was done, and continues to be done, for short-term individual profit and now, as a nation, we are slowly realizing that things must change. But, how to change? That is where leadership is required, and where crisis management and ecological restoration meet.

Crisis management, which emerged in recent decades from military and business management, seeks to understand and control those disastrous events that would otherwise catch us offguard. These events run the gamut from natural disasters to human-caused emergencies. Simply put, crisis management operates in four general modes:

- detect potential signals of a crisis

- reduce identified risks as a means of preventing a crisis

- prepare for and manage crisis situations that could not be prevented

- plan and implement restorative activities

These modes of action rely heavily on shared information and scientific knowledge to carry out their mission.

The governmentís current major crisis management strategy in the western forests is to put tax dollars into fighting fires-an activity that fits into the third mode of crisis management. Spending money on this activity will continue as long as the Forest Service and the public believe that they are preventing a crisis that is defined by an effect, namely, catastrophic fire and the loss of property. Minds are changing, however, as people begin to realize that the current approach is not working; that fighting fires is a Sisyphus-like task. Attitudes are also changing because scientists and the media are doing a better job of disseminating scientific information about the role of fires in fire-dependent ecosystems. It is true that we that we remain uncertain exactly what to do, vulnerable as to the validity of our assumptions and long-cherished beliefs. However, we are starting to think creatively. We now are looking at causes rather than effects and searching for solutionsand those solutions, it appears, include ecological restoration.

Because much of what we are witnessing in terms of degraded and/or fire-prone forested ecosystems is due to outmoded and destructive government policies, citizens in the western states have turned to their state governments, who in turn have looked to the federal government for guidance and fiscal support. The result is President Bush's Healthy Forests Initiative, which I can only describe as an enigmatic crisis management plan. Enigmatic because it has some potential to be restorative, yet it obfuscates that potential by including legal actions designed to limit essential debate and dialogue in the name of immediate security. True crisis management, like sound ecological restoration, means sharing ideas with everyone involved, while at the same time trying to understand and solve the problem. And true ecological restoration, like sound crisis management, means being in it for the long haul. We must remember that it will take time no matter what we do to restore the western forests. We should not expect to complete the job during one administration or even during one lifetime.

Finally, looking into the issue of restoration in the western forests has convinced me that we need leaders who will bring ecological restoration into the political and social dialogue. To that end, I think the Society for Ecological Restoration International should become politically active on national and international issues of this magnitude. Yes, individuals, like Wally Covington, Dominick DellaSala and others, will continue to push forward with new ideas and solutions, and their work certainly demands and deserves SERI's support. More importantly, however, SERI needs to take positions on important issues both to raise the profile of the organization and to maintain the integrity of our practice and principles. To do anything less would be evading our civic responsibility and would fail to protect our hopeful enterprise from those who would misinterpret it as they seek answers to critical problems.

Dave Egan 